\title{
The Dark Side of Competitive Pressure*
}

\author{
Jason G. Cummins \\ Division of Research and Statistics \\ Federal Reserve Board \\ jason.g.cummins@frb.gov
}

\author{
Ingmar Nyman \\ Department of Economics \\ Hunter College, CUNY \\ ingmar.nyman@hunter.cuny.edu
}

August 25, 2002

\begin{abstract}
One of the most basic principles in economics is that competitive pressure promotes efficiency. However, this pressure can also have a dark side because it makes firms reluctant to act on private information that is unpopular with consumers. As a result, firms that possess superior information about the consequences of their actions for consumers' welfare may choose not to use it. We develop this idea in a simple model of delegated investment in which agents are fully rational and risk neutral, and agency problems are absent. We show that competitive pressure obliges firms to make inefficient decisions when their information advantage over consumers is relatively small. This result could be applied to a broad range of economically important situations.
\end{abstract}

JEL Classification: D20; D40; D82.

Keywords: Competition; Information Aggregation; Incentives.

\footnotetext{
${ }^{*}$ We thank Darrel Cohen, Alessandro Lizzeri, and seminar participants at the CUNY Graduate Center and Hunter College for their comments. The views presented are solely those of the authors and do not necessarily represent those of the Federal Reserve Board or its staff.
} 


\section{Introduction}

In this paper, we point out a cost that can be caused by competitive pressure. Normally, the threat of competition forces firms to make decisions that are in the consumers' best interest. But consider the situation in which firms are better informed than the consumers. In this case, competitive pressure makes it costly for firms to utilize their information if it contradicts consumers' opinions. In effect, there's always another firm that stands ready to cater to my customer if I fail to do so. Hence, competitive pressure encourages firms to seek market share by pleasing the relatively uninformed consumers. This desire may prevent firms from utilizing their private information, which reduces social welfare. Agency problems - the usual cause of inefficiency when there is private information - play no role in the inefficiency we highlight because the inefficiency occurs even when the interests of firms and consumers are perfectly aligned.

An example helps convey the intuition. Consider a benevolent investment manager who invests her client's resources with the aim of maximizing the expected return. There are two alternatives, buying equity in a dot-com or in a widgetmaker. The client believes that the dot-com is the superior investment, perhaps because of the recent history of share prices. However, the investment manager, who as an expert has better information than the client, believes that the widgetmaker is a better investment. In the absence of competition, the manager invests in the widget-maker, even though the client believes — probably incorrectly — that this is the wrong choice. However, if there is a second investment manager who believes that the dot-com is a better bet, then the client will invest with that manager. Knowing that competition poses this threat, the first manager may be obliged to go against her better judgment and offer to invest in the dot-com in order to keep the client. From a social planner's perspective, it is undesirable to cater to the client in this way because the firm's private information is not fully utilized. 
This type of delegated investment framework is the setting in which we formalize our argument. In our model, we assume that all agents are fully rational and risk neutral, and that the interests of consumers and firms are perfectly aligned. In this setting, competitive pressure, by itself, can force investment managers to make inefficient investment decisions in order to appeal to consumers' priors. Interestingly, making the consumer better informed can actually worsen the inefficiency. Since consumers are often less well-informed than firms, our insight is potentially important in many situations. We discuss possible applications after having introduced and discussed the model.

The idea that pleasing the uninformed distorts the incentive to reveal and use private information is at the heart of the literature on managerial myopia (see Grant, King, and Polak 1996 for a survey). In this literature, a corporate manager who has private information - either in the form of a hidden action or hidden information - and who cares about the current share price has an incentive to distort investment in an attempt to manipulate the stock market's information. In particular, the manager avoids investment that the stock market either does not want to see (hidden information) or is unable to see (hidden action). For our purposes, the most powerful analysis of this problem is due to Brandenburger and Polak (1996), who demonstrate that the manager avoids investment not because it reveals information that is objectively bad, but because it reveals information that contradicts the prior opinions of the stock market. As a consequence, the manager makes "the decisions that the market wants to see." What drives Brandenburger and Polak's result is the assumption that managers care about others' opinions. In our model, this type of concern is created endogenously by competitive pressure.

Our work also complements Prendergast (1993), who shows that employees who are rewarded based on the subjective performance evaluation of their superior have a tendency to become "yes men." Prendergast frames his analysis as an inherent conflict between incentives and the use of information, which is precisely the perspective we have. But while Prendergast makes his argument in a situation where incentives 
are provided by a compensation contract, we argue that competition creates the same sort of tension between incentives and the use of information.

In addition to competition and explicit contracts, reputational concerns can also provide incentives. Holmström (1982) first pointed out that reputational considerations can distort production decisions and lead to inefficiencies because agents try to manipulate the information that they reveal. Scharfstein and Stein (1990) elaborate on this conclusion by showing that private information may be wasted when there are multiple producers who move sequentially. By ignoring their own information and instead mimicking the decisions of others, producers are trying to be perceived as capable. Morris (2001) demonstrates that the same type of wasteful disregard for private information can occur when the informed party is an advisor rather than a decision maker and her worries about reputation are instrumental (i.e., driven by concern for future decision-making) rather than intrinsic (i.e., driven by concern for future perceptions of herself).

The paper that bears the most immediate resemblance to ours is Heidhues and Lagerlöf (2002). ${ }^{1}$ They study an election game and show that a candidate with private information about different policy alternatives will pander to the electorate in order to achieve her sole goal of being elected. This is truly insightful application of the idea that information may be used inefficiently when the informed need to cater to the uninformed. The key difference between their analysis and ours lies in the relationship between the informed and the uninformed. Heidhues and Lagerlöf assume that there's a conflict of interest that makes candidates use information inefficiently: their politicians care only about the uninformed short-term beliefs of voters and not at all about the real long-term consequences of their actions for the electorate. Formally, their model is a cheap-talk game in which signals are costless, and it is a standard result in this literature that the informed sender may change the signal in order to manipulate the receiver's information. By contrast,

\footnotetext{
${ }^{1}$ Thanks go to Alessandro Lizzeri, who brought this paper to our attention after we completed ours.
} 
our model is not a cheap-talk game because we assume that firms have the best long-run interest of the consumers at heart. We show that even when interests are perfectly aligned in this way, the incentive to behave inefficiently in an attempt to manipulate the revelation of information may arise endogenously because of the presence of competitive pressure.

The rest of the paper is organized as follows. In the next section, we develop a simple model to illustrate our argument. In section 3, we discuss the model and possible applications. The final section concludes, and the two appendices contain technical details.

\section{The Model}

After setting up the model in the following subsection, we analyze the solution when there is a single firm. This monopoly case serves as a benchmark for the main case with two competing firms. We close the section with a discussion of the solution with an arbitrary number of firms. The importance and restrictiveness of the numerous simplifying assumptions are discussed in Section 3.

\section{$2.1 \quad$ Setup}

The model formalizes the informational inefficiency resulting from competitive pressure in a highly stylized delegated investment problem, based loosely on Brandenburger and Polak (1996). In the model, a single consumer invests a dollar with firms that have superior information about the expected profitability of different projects. The consumer is denoted by the subscript $c$ and the firms are denoted by the subscripts $i$ and $j$. There are two time periods. In the first period, each firm offers an investment strategy. In the second period, the consumer allocates her investment between the projects and the investments generate a payoff. The consumer receives half of this payoff, while the firm (or firms) that made the investment receives the other half. 


\subsubsection{Investment Management}

There are two investment projects — "green" and "red" — denoted by $z \in\{g, r\}$. The investment payoff $\pi$ depends on two possible states of the world - "Green" and "Red" - denoted by $Z \in\{G, R\}$. In the Green state the highest payoff is from the green project and in the Red state the highest payoff is from the red project. To simplify the analysis, the "high" and "low" payoffs (net of investment) are the same for both the green and red project. The high and low payoffs are normalized to one and zero, respectively. Formally, the net payoff function from the investment of one dollar is

$$
\pi(z, Z)= \begin{cases}1 & \text { if }(g, G) \text { or }(r, R) \\ 0 & \text { if }(g, R) \text { or }(r, G)\end{cases}
$$

Without loss of generality, the prior distribution on the state space, which is known to everyone, is $\operatorname{Pr}(Z=G)=\mu \geq \frac{1}{2}$.

In the first period, each firm offers an investment project with the objective of maximizing its own expected profit. ${ }^{2}$ When making this choice, the firms have private information in the form of a signal about the state of the world. The signal process is the same for both firms and their signals are conditionally independent. The signals take on one of two realizations, $\gamma$ or $\rho$, and are denoted by $s \in\{\gamma, \rho\}$. A $\gamma(\rho)$ signal is an indication that the state is Green (Red). Both signal realizations have the same accuracy, denoted by $\sigma: \operatorname{Pr}(\gamma \mid G)=\operatorname{Pr}(\rho \mid R)=\sigma>\frac{1}{2}$. The firms can use mixed strategies with the probability that a firm chooses the green project conditional on its signal denoted by $\beta^{s} \equiv \operatorname{Pr}(z=g \mid s)$, where the superscript indicates dependence on the realization of a firm's private signal.

The normalization of the payoffs makes the expected value of the projects equal to the probability that the state is the matching one. To make the problem interesting, we assume that the firms' private information is superior to the publicly available information, so that $\sigma>\mu$. This motivates the firms' presence in the

\footnotetext{
${ }^{2}$ We thus assume that the firms can credibly commit to a certain investment policy through an offer, which seems reasonable since both the offer and the investment are likely to be verifiable.
} 
model by allowing them to contribute something to the investment decision. It also makes it efficient for the firms to follow their signal.

We denote the first-best efficient investment strategy that maximizes the $e x$ ante expected investment payoff by $\beta^{* *}=\left(\beta^{\gamma}=1, \beta^{\rho}=0\right)$. In words, the first best efficient strategy is the one in which the green (red) project is picked with certainty by a firm that receives a $\gamma(\rho)$ signal. The resulting expected payoff is $\mathrm{E}\left[\pi\left(\beta^{* *}\right)\right]=\operatorname{Pr}(G) \operatorname{Pr}(\gamma \mid G)+\operatorname{Pr}(R) \operatorname{Pr}(\rho \mid R)=\mu \sigma+(1-\mu) \sigma=\sigma$. Hence, if a firm invests efficiently, it creates an expected value-added equal to the information that its signal adds over and above the consumer's information, i.e., $\sigma-\mu$. Finally, the efficiency loss from any investment strategy, $\beta$, is denoted by $W(\beta)$ and is defined as the shortfall in expected payoff compared to that of the first-best efficient strategy: $W(\beta) \equiv \mathrm{E}\left[\pi\left(\beta^{* *}\right)\right]-\mathrm{E}[\pi(\beta)]$.

\subsubsection{Trading and Consumer Behavior}

After observing the investment projects offered by the firms, the consumer chooses how much to invest in each project with the objective of maximizing her expected payoff. When the consumer chooses a project, we assume that she receives half of the payoff from that investment, and that the other half goes to the firm that offered the project. The assumption that the investor and the firm split the return from the investment is important because it aligns the long-run interests of the consumer and the firm, who would both prefer that the investment yield a high payoff. This means that agency problems play no role in generating our conclusions and furthermore that they are robust to the introduction of mechanisms that address agency problems such as explicit contracts or reputational concerns through repeated interaction.

From the consumer's point of view, both investment projects always have a strictly positive expected payoff. Not investing at all is therefore a strictly dominated strategy for the consumer, so she need only choose the fraction of her wealth to invest in the green project, denoted by $\alpha \in[0,1]$. Of course, the consumer can invest only in projects that are offered. As a result, if both firms offer green (red) projects, the 
consumer's choice is restricted to $\alpha=1(\alpha=0)$. When this happens, we assume that the consumer splits her dollar evenly between the projects offered by the two firms. The purpose of this assumption is to eliminate any extraneous differences in firms' competitiveness in order to focus on how competitive pressure, by itself, affects their choice of project type.

\subsection{Equilibrium with Monopoly}

Turning to the analysis of the model, consider first the case when there is a single firm. The consumer gives her dollar to the firm to invest no matter what investment strategy the firm pursues. Therefore, the firm is unconcerned about making sure the consumer provides it with resources to invest. Instead, the firm can choose the investment project based solely on its long-run payoff. Since the firm gets a share of those long-run payoffs, it chooses the first-best efficient investment strategy:

$$
\begin{aligned}
& \pi_{i}(z=g \mid \gamma)=\frac{1}{2} \operatorname{Pr}(G \mid \gamma)>\frac{1}{2} \operatorname{Pr}(R \mid \gamma)=\pi_{i}(z=r \mid \gamma) \Rightarrow \beta^{\gamma^{*}}=1 \\
& \pi_{i}(z=r \mid \rho)=\frac{1}{2} \operatorname{Pr}(R \mid \rho)>\frac{1}{2} \operatorname{Pr}(G \mid \rho)=\pi_{i}(z=g \mid \rho) \Rightarrow \beta^{\rho^{*}}=0 .
\end{aligned}
$$

The ex ante expected total payoff - to be split evenly between the consumer and the firm - is equal to $\sigma$.

\subsection{Equilibrium with Two Firms Competing}

Suppose instead that two firms compete for the consumer's investment funds. This gives the consumer a non-trivial choice between two investment projects (if both are offered). The consumer always prefers the project with the greater expected payoff. Since the consumer cannot observe the firms' signals, she must instead base her inference about the true state of the world on only her own prior beliefs, captured by $\mu$, and the firms' choices of project.

The key observation in this situation is that in a perfectly-separating efficient equilibrium, the consumer's posterior beliefs will typically favor one project over the other. This situation occurs generically, with the green project having a competitive 
advantage whenever $\mu>\frac{1}{2} \cdot{ }^{3}$ When the consumer's preference is skewed in this way, it enhances the incentive for a firm with a $\gamma$-signal to behave efficiently and choose the green project; not only does the green project yield a higher return than the red project, but if the other firm offers a red project, the firm offering the green project captures the entire market. If the other firm offers a green project as well, the consumer splits her dollar between the two green projects.

But for a firm with a $\rho$ signal the first-best efficient strategy of investing in the red project now presents a dilemma: with this signal, the expected value of the red project is higher, but its expected market share is lower since the consumer prefers the green project when it is offered. This trade-off is determined by the relative strength of the consumer's prior that green is the better project, captured by $\mu$, and the $\rho$-type firm's conviction that it is not, captured by $\sigma$. If the $\rho$-type firm is sufficiently confident that the state is Red - i.e., $\sigma$ is sufficiently large compared to $\mu$ - then the red project will be chosen, which is efficient. But if the signal is weak — i.e., $\sigma$ is sufficiently small compared to $\mu$ - then the $\rho$-type firm finds it optimal to ignore its private information and instead cater to the consumer's belief that the green project is the correct one. This intuition is summarized in Proposition 1 and illustrated in Figure 1.

Proposition 1: With two firms, the first-best efficient outcome is not an equilibrium when the consumer's prior belief favors one state over the other and the firms' information advantage over the consumer is sufficiently small.

Proof: See Appendix.

Figure 1 illustrates the efficient and inefficient regions derived in Proposition 1. The basic idea is simple: the $\rho$-type firm may want to offer the green project to

\footnotetext{
${ }^{3}$ Eliminating the competitive advantage for one of the projects is even more difficult than this condition suggests. As Brandenburger and Polak (1996) show, in a perfectly-separating first-best efficient equilibrium, the consumer has access to the firms' signals, so her posterior beliefs depend on her own prior, the payoffs from the investment projects, and the accuracy of the firms' signals. Our model has already imposed a non-generic symmetry in investment payoffs and signal quality.
} 


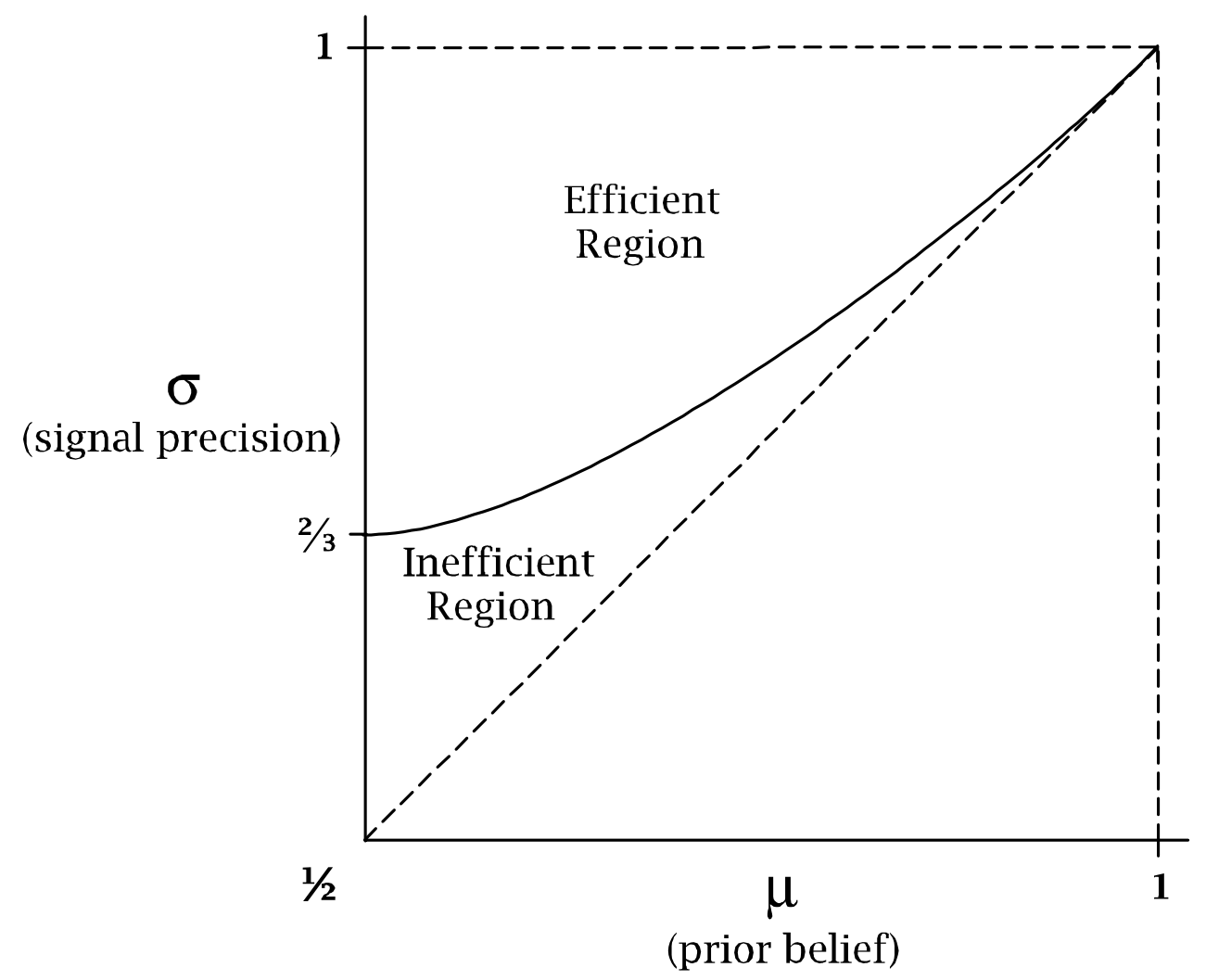

Figure 1: Efficient and inefficient regions 
capture market share. For some combinations of $\sigma$ and $\mu$, the incentive is strong enough to break the efficient equilibrium. For a given $\sigma$, pick a number like $\frac{3}{4}$ in the figure, consider increasing $\mu$; eventually, the consumer's prior gets skewed enough to break the efficient equilibrium. For a given $\mu$, again pick a number like $\frac{3}{4}$, consider increasing $\sigma$; eventually, the firm's private information becomes precise enough to restore the efficient equilibrium.

In the inefficient region of the parameter space, the firms play a partially separating equilibrium in which investment is inefficient. A $\gamma$-type firm invests efficiently by always choosing the green project. By contrast, a $\rho$-type firm invests inefficiently, playing a mixed strategy that invests in the green project with strictly positive probability. In equilibrium, the consumer is indifferent between the red and the green project, and splits her dollar between the two when they are both offered. The equilibrium is derived in Proposition 2.

Proposition 2: In the inefficient region derived in Proposition 1:

1. A $\gamma$-type firm invests efficiently: $\beta^{\gamma^{*}}=1$.

2. A $\rho$-type firm invests inefficiently: $\beta^{\rho^{*}}=\widehat{\beta}^{\rho} \equiv \frac{\sigma(1-\sigma)(2 \mu-1)}{\sigma^{2}(1-\mu)-(1-\sigma)^{2} \mu} \in(0,1)$.

3. The consumer splits her investment between the green and the red project when both are offered: $\alpha^{*}=\left(\frac{\sigma}{1-\sigma}\right)\left(\frac{1-\mu}{\mu}\right) \in\left(\frac{1}{2}, 1\right)$.

4. The efficiency loss due to competition is equal to $W=(\sigma-\mu) \widehat{\beta}^{\rho}$.

Proof: See Appendix.

Figure 2 illustrates the economics of the inefficient equilibrium. In panel A, we graph the $\rho$-type firm's net benefit from choosing the green project when the $\gamma$-type firm invests in the green project with probability one, denoted $\Pi_{i(g-r)}^{\rho}$. For low levels of $\beta^{\rho}$, the benefit is strictly positive because the green project has the competitive advantage over the red one. However, at $\widehat{\beta}^{\rho}$, the consumer switches to 


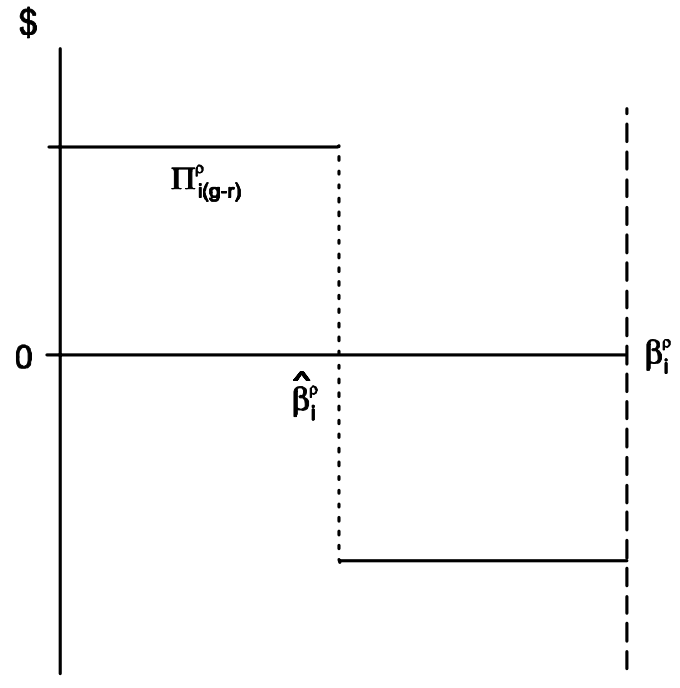

(A)

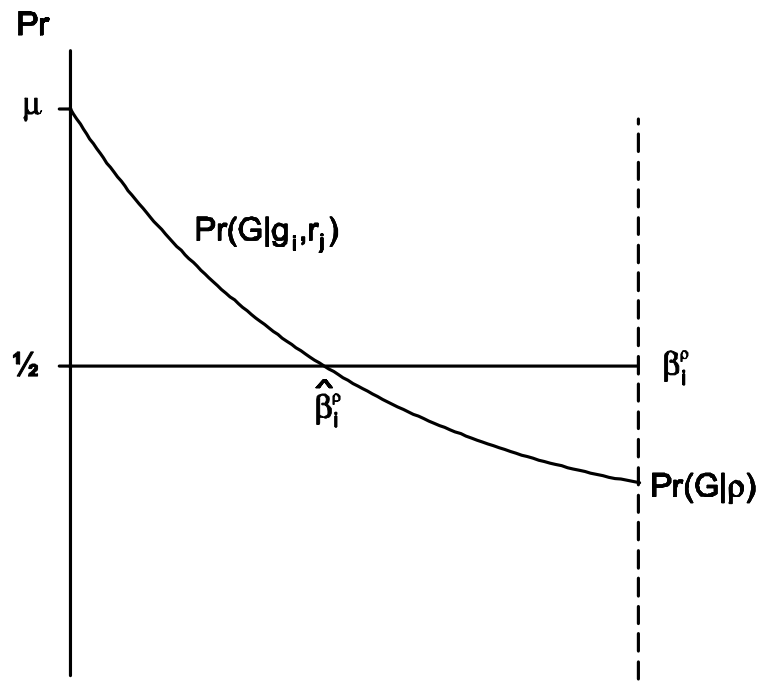

(B)

Figure 2: Net benefit from the green project to the $\rho$-type firm and the consumer

choosing the red project over the green one, which makes the net benefit from the green project strictly negative for high levels of $\beta^{\rho}$. The reason for the consumer's preference reversal is that by putting more weight on the green project, the $\rho$-type firm garbles the consumer's inference about the green project's profitability. This is illustrated in panel $\mathrm{B}$ : At $\widehat{\beta}^{\rho}$ the consumer is indifferent between the green and the red project, so any choice of $\alpha$ is best response to $\widehat{\beta}^{\rho}$. The choice of $\alpha$ by the consumer can therefore bridge the discontinuity at $\widehat{\beta}^{\rho}$ in the $\rho$-type firm's net benefit from choosing the green project. We call $\alpha^{*}$ the unique value of $\alpha$ that makes the $\rho$-type firm indifferent between the green and the red project, so that $\widehat{\beta}^{\rho}$ is a best response. Since $\widehat{\beta}^{\rho}$ depends only on the information structure and the firms are identical, they must both choose $\widehat{\beta}^{\rho}$ in equilibrium if they receive a $\rho$ signal. Moreover, this equilibrium behavior by the firms, $\beta^{\gamma^{*}}=1, \beta^{\rho^{*}}=\widehat{\beta}^{\rho}$, makes $\alpha^{*}=\left(\frac{\sigma}{1-\sigma}\right)\left(\frac{1-\mu}{\mu}\right)$.

It is worth pointing out that the $\rho$-type firm's equilibrium strategy has a discontinuity at the boundary in parameter space between the inefficient and efficient 
regions (see Figure 1). When moving across the boundary from the inefficient to the efficient region, $\beta^{\rho^{*}}$ falls discontinuously from $\widehat{\beta}^{\rho}>0$ to 0 . This can be seen in Figure 2A, where a move toward the efficient region pushes the net benefit from inefficient investment down. At the boundary, the segment in the upper-left-hand side, which is positive in the inefficient region, reaches zero, but the discontinuity in the net benefit function is still interior, i.e., $\widehat{\beta}^{\rho}$ is strictly positive at the boundary.

The efficiency loss from competition is economically intuitive. The inefficiency comes from firms failing to use completely their valuable private information when the realization of the $\rho$ signal puts them at odds with the consumer's preconceptions. The efficiency loss is therefore the expected value of the firm's information, $\sigma-\mu$, multiplied by the probability that it gets wasted by the $\rho$-type firm, $\widehat{\beta}^{\rho}$.

The comparative static analysis of the inefficient equilibrium reveals that the extent to which the $\rho$-type firm invests inefficiently, $\widehat{\beta}^{\rho}$, increases with $\mu$ and decreases with $\sigma$. The reason is that $\widehat{\beta}^{\rho}$ reflects the dose of the $\rho$-type firm's contradictory information that it takes to dissuade the consumer of her initial preference for the green project. It is economically sensible that this required dose increases with the strength of the initial belief, $\mu$, and decreases with the accuracy of the new information, $\sigma$. By contrast, $\alpha^{*}$ decreases with $\mu$ and increases with $\sigma$. This is because the consumer's equilibrium allocation to the green project is determined by what makes the $\rho$-type firm indifferent between choosing the green and the red project. Therefore, the consumer's allocation to the green project must decrease in order to compensate for it becoming more attractive to the $\rho$-type firm when $\mu$ increases or $\sigma$ decreases.

As illustrated in Figure 3, the dependence of the efficiency loss, $W$, on the information structure is considerably more complicated. The most interesting observation about this picture is that the efficiency loss is non-monotonic in $\mu$. Hence, making the consumer better informed - by increasing $\mu$ - may make matters worse, increasing the inefficiency from competitive pressure. What happens in this 


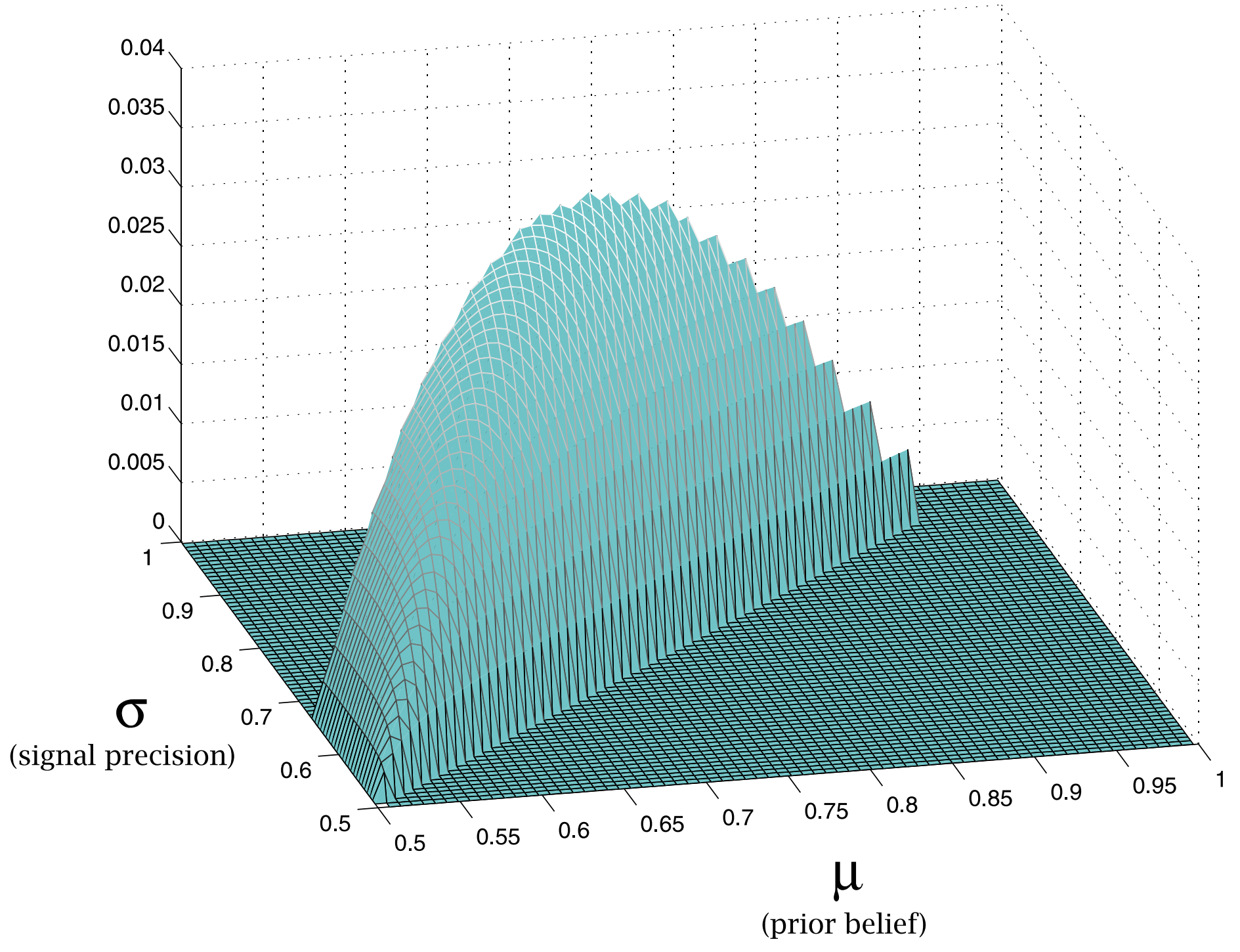

Figure 3: The Efficiency Loss From Competitive Pressure 
case is that firms waste more information by paying closer attention to the consumer's opinion, despite the fact that an increase in $\mu$ makes the firms' information less valuable.

\subsection{The Number of Firms}

It is natural to ask what happens to our results when the number of firms increases. Unfortunately, the general analysis is intractable. Nevertheless, to get a feel for the economic forces at work, we derived analytical solutions when there are three and four firms. For the most part, the economics of the analysis is intuitive, but the formality of it is rather cumbersome (see Appendix B). The basic conclusion - that the inefficiency from competitive pressure diminishes with the number of firms is probably not surprising.

There are two effects when the number of firms increases. First, the probability of being pivotal decreases. In a fully-separating efficient equilibrium, the consumer has access to all private information, so a firm can be pivotal only if the signals of all the firms cancel out. Obviously, the probability of such an informational stalemate decreases with the number of firms. ${ }^{4}$ Second, when the number of firms increases, so does the amount of total private information. This makes it more costly for the $\rho$-type firm to disregard its own private information.

It is intuitive that the inefficiency from competitive pressure shrinks with the number of firms. After all, we have already shown that the inefficiency disappears when the individual firm's information advantage over the consumer becomes sufficiently large. As the number of firms increases, their aggregate information advantage over the consumer increases, and because the information is correlated

\footnotetext{
${ }^{4}$ This also implies that when there is an odd number of firms, the inefficiency disappears: with an odd number of firms, all the information cannot cancel out. With three firms, for example, there are at least two $\gamma$-type firms or at least two $\rho$-type firms, so the consumer would always choose the project that is offered by a larger number of firms. As a consequence, the pivotal firm does not have to misrepresent its information in order to make the consumer choose its project. However, the distinction between an odd and an even number of firms is not a robust piece of economic intuition, but rather a peculiarity of the specific modeling approach that we use.
} 
across firms, the expected cost for each firm of disregarding its own information increases as well.

Nevertheless, increasing the number of firms without contemplating any other changes may not be the best thought experiment. Consider, for example, the mutual fund industry. There are thousands of competitors but that does not mean that there is complete information about which fund is best. The main reason why comes from ignoring product differentiation, which tends to shield firms from competitive pressure. More specifically, if the differentiated characteristic has an objective component, then competition is localized; in effect, each firm competes with only its closest neighbors in the product space (see Eaton and Lipsey 1989 for a survey of the literature on product differentiation). Therefore, even if the number of firms in the market as a whole is large, product differentiation makes all but a small number of them irrelevant to any one firm. ${ }^{5}$ As a consequence, product differentiation may offset the tendency toward efficiency when the number of firms increases.

More generally, our model is one of product choice, and the economic forces at work are similar to those found in the product differentiation model introduced by Hotelling (1929). ${ }^{6}$ Hotelling derived the celebrated "principle of minimum differentiation," which refers to the tendency of product choice to be bunched together in order to gain market share. The tendency in our model for producers to cater to the consumer and offer her favorite project even when it is inferior is an example of this principle. More generally, when making product choices, one incentive for firms is to "be where the demand is" (Tirole 1988, p. 286). If consumers know less than producers about the product choice, then this incentive, which is accentuated by competition, may pull firms away from choices that are objectively better.

\footnotetext{
${ }^{5}$ However, the larger is the number of dimensions in which the product is differentiated, the weaker is the tendency towards a localization of competition (Eaton and Lipsey 1989).

${ }^{6}$ The sharp discontinuity in the model's conclusions when there is an odd number of firms is also reminiscent of a peculiarity of the Hotelling model: if prices are fixed, then no pure-strategy Nash equilibrium in product characteristics exists when there are three firms in the market (Eaton and Lipsey 1975).
} 
In Hotelling's model, there is also a tendency to move away from minimum differentiation. When firms locate close to each other, price competition tends to decrease the value of their product choice even if their market share is high. Our model also has a cost to minimum differentiation, but the economics is quite different: a product choice has a lower per-unit expected value not because of the presence of competitors, but rather because it is an intrinsically inferior choice in light of the information about the uncertain investment environment.

\section{Discussion}

\subsection{Assumptions}

There are a number of assumptions of the model that warrant discussion. First, because the payoffs of all players are proportional to the expected payoff from investment, the interests of the firms and the consumer are perfectly aligned. This assumption eliminates any agency problems in order to focus on the informationaggregation aspect of competition, creating a benchmark of first-best efficiency under monopoly. Obviously, in the presence of agency problems, competition would have incentive benefits that could offset its informational costs. But the fact that our results emerge even when incentive problems are absent makes them especially striking. The inefficiency from competition that we highlight has nothing to do with firms paying insufficient attention to the customer's true long-run interest. On the contrary, the point that we make is that competition endogenously distorts producer incentives away from being concerned about long-run consumer value toward being concerned about short-run consumer opinions. When these opinions may be erroneous due to lack of information, competition may force firms to make inefficient choices.

Second, we have not considered alternative mechanisms that might restore efficiency. In particular, efficiency could be restored if the consumer were able to conceal her prior. One way to do this is to let the consumer choose how to allocate her investment after the firms have made their offers. Then the firms would 
ignore the consumer's opinion if she promised to split her dollar evenly across the firms regardless of their investment choice. Although this seems like an attractive arrangement at first glance, we believe that we have given the game a more reasonable dynamic structure for two reasons. First, the consumer's promise is not credible: once the firms offered their investment strategy, it would be in the consumer's best interest to go back on her promise and choose instead the firm that offers the project that the consumer perceives has the highest expected payoff. The consumer may, of course, find ways to precommit, for example through an explicit contract, but such contracts appear exceedingly rare. Second, a conflict of interest between the consumer and the firms is likely to be present as well, in which case the consumer would be reluctant to relinquish her ability to respond to actions taken by firms.

Third, the firms can compete only through product choice. A natural second dimension of competition would be through pricing. This could be modeled if we allowed the firm to cede a larger share of the investment payoff. Although this extension may alter the analysis significantly in some applications, we conjecture that in the current model it would not change the flavor of the results: it seems likely that Bertrand-like competition would shrink the firm's payoff share, but otherwise leave the analysis unchanged. ${ }^{7}$

Fourth, the investment projects are indivisible. In some applications, it would be sensible to allow for compromises between different alternatives. For example, we could certainly allow the firms to offer a portfolio consisting of both projects. However, no firm would take that opportunity. Obviously, the $\gamma$-type firm has no use for anything but the green project, which means that any portfolio containing the red project reveals perfectly that the firm has a $\rho$ signal. But in the inefficient region,

\footnotetext{
${ }^{7}$ Some caution is warranted, however, because an equilibrium does not exist in many games in which firms choose both price and product characteristics (see, for example, Caplin and Nalebuff 1991 and d'Aspremont, Gabszewicz, and Thisse 1979). We conjecture that this is a non-issue in our model because there is no interaction between price and product location: the cost of locating close to another firm is not due to stiffer price competition, but rather due to that location being intrinsically inferior.
} 
perfect separation makes the red project strictly inferior to the green one, even if the firm has a $\rho$ signal, so a mixed portfolio would never be used in equilibrium.

Fifth, the consumer is forced to rely on the firms' expert investment management because she lacks a viable investment option that she can manage on her own. Without this assumption, the consumer herself might, in effect, put competitive pressure on the firms by partly acting as an investment manager in her own right. This could make the distortions in the firms' investment strategy appear even under monopoly. However, the essence of the economic argument would nonetheless remain intact since competitive pressure - albeit from the consumer rather than from other firms - would still be what forces firms to cater to the consumer's uninformed preference.

Finally, in our model, the firms supply their expertise by offering products. An alternative is that they sell their advice to the consumer, who then makes the investment decision herself. However, as long as the firms' have valuable information and their compensation depends only on the ultimate payoff from the investment that the consumer herself makes, the analysis is unaffected. The important point is that competition allows the consumer to choose the firm that says what she wants to hear, be it in the form of advice about, or the execution of, her investment decision.

\subsection{Applications}

Although we cannot hope to capture the full richness of real world problems using our very parsimonious model, there do appear to be many situations in which competitive pressure can impede the management of private information. Here are several examples in which our results may be an important element of the story:

- Savings and Loan Crisis

Milgrom and Roberts (1992) say that competitive pressure was one of the key forces in the S\&L crisis of the 1980s: "The moral hazard problem in the S\&L industry was actually intensified by the effects of competition. Normally we think of competition, which tends to drive out those executives who are 
unwilling to take the profit-maximizing actions, as promoting efficiency. In the context of the S\&L industry in the 1980s, however, competition had a perverse effect. Many conservative S\&L executives had no choice but to gamble on risky investments if they were to survive." (p. 175).

- Credence Goods

With credence goods, an expert must act as the agent for the customer in making production decisions, and it is difficult for the customer to evaluate the quality of the expert's decision-making even ex post. Examples include medical services, legal services, and repair services. The literature on credence goods has focused on the problem of agents who exploit customers' information disadvantage (see Dulleck and Kerschbamer 2001 for a survey). However, against the backdrop of the analysis presented here, it is natural to ask whether competition can force experts to cater to the customer's uninformed, short-run opinion rather than pursue her long-run welfare.

Anecdotes suggest that this problem is especially important when it comes to prescription drugs. Patients demand certain widely advertised drugs from doctors (see, e.g., Nexium which is marketed as the "purple pill" so it's easy for consumers to remember). Doctors usually know better than their patients whether the "purple pill" and the like is appropriate. Nevertheless, doctors prescribe brandname drugs, rather than generics, for fear of upsetting the consumer, according to reports. ${ }^{8}$

- Competition for Votes

In many countries, there is a continuing constitutional debate over how often politicians should face the voters. The standard argument for holding elections with lower frequency is that it shields politicians from competitive pressure that may force them to make populist decisions that are not in the

\footnotetext{
8 "Prilosec's Maker Switches Users to Nexium, Thwarting Generics," Wall Street Journal, p. A1. June 6, 2002.
} 
best long-run interest of the country. In support of this view, Heidhues and Lagerlöf (2002) argue that self-interested political candidates have an incentive to choose political platforms that get them elected, rather than those that implement efficient outcomes. Our analysis suggests that this conclusion is not limited to when politicians are self-interested, but that it applies even when candidates have the electorate's best interest in mind.

- Internal Labor Markets

Organizations are an important arena where management of information on behalf of others takes place. Holmström and Milgrom (1991) were the first to point out that incentive provision is delicate when decision-making is complex. Prendergast (1993) applies this idea to information management, and establishes a trade-off between incentive provision and information aggregation when incentives are provided through compensation contracts. But incentives can also be provided by internal labor markets in which employees compete for promotion (see, e.g., Lazear and Rosen 1981). Our analysis suggests that even though competition can induce employees to supply the efficient amount of labor, it may also give them the incentive to use private information relevant to the firm's profits in an inefficient way. ${ }^{9}$ In other words, Prendergast's "yes men" may be the result not only of incentive contracts, but of the competition for promotion as well.

\section{Conclusion}

Our model establishes that competitive pressure can lead to inefficient decisions when producers are better informed than consumers about the benefits of different alternatives. Consumers typically have a favorite alternative, which gives producers the incentive to enhance their competitiveness by choosing that project, even when

\footnotetext{
${ }^{9}$ There are, of course, other important disadvantages to incentive provision through competition as well, most notably that it discourages cooperation among employees (Lazear 1989) and may lead to costly influence activities if the evaluation of performance is subjective (Milgrom 1988, Milgrom and Roberts 1988, and Tirole 1992).
} 
their own expert opinion suggests otherwise. However, the efficiency cost of choosing the wrong alternative provides firms with a countervailing incentive to ignore the consumer's preferences, and to act on their superior private information. Therefore, the inefficiency from competition disappears when the producers' information advantage becomes sufficiently large.

This insight is only a first step in our research, so the agenda for refinements and extensions is extensive. First, we want to extend the model so that competition has an incentive benefit as well as an information-aggregation cost. This would allow for an explicit analysis of the relationship between the two and how the tradeoff between them depends on the economic environment. Second, an intriguing extension of the model would be to allow for the customer to be a firm. To make this interpretation interesting, we would like to incorporate an additional layer of agency problems between management and shareholders in the demand-side firm. The market for auditing services could be one application of this formulation of the model. Third, it would be interesting to try to transplant the economics of our model to the Lazear-Rosen framework of incentive provision through rank-order promotion tournaments. Finally, we have shown that competition prevents private information from being used, which begs the question of whether competitive pressure puts a damper on experimentation and the acquisition of private information. 


\section{A Proofs of Propositions}

Proof of Proposition 1: In a perfectly-separating equilibrium the firms invest efficiently, so the consumer can infer the firms' signals perfectly. If the two firms have different signals and therefore offer different projects, then the consumer's payoff from choosing the green project looks as follows:

$$
\mathrm{E}[\Pi(g) \mid g, r]=\mathrm{E}[\Pi(g) \mid \gamma, \rho]=\operatorname{Pr}(G \mid \gamma, \rho) \cdot 1+\operatorname{Pr}(R \mid \gamma, \rho) \cdot 0=\mu \geq(1-\mu) .
$$

Suppose that $\mu=\frac{1}{2}$. The consumer now splits the dollar evenly between the two projects if both are offered, so the firms receive the same payoff from both projects in case they have different signals. When the firms receive the same signal, choosing the efficient investment project yields a strictly higher payoff. Hence, if $\mu=\frac{1}{2}$, then efficient investment is an equilibrium.

Suppose instead that $\mu>\frac{1}{2}>(1-\mu)$. Now the consumer always chooses the green project if the firms offer different projects. Therefore, in case the firms receive different signals, the firm that receives a $\rho$ signal stands to gain from switching to the inefficient investment project, which could make the efficient outcome strategically unstable. The firm with a $\gamma$-signal, on the other hand, clearly has no incentive to deviate).

Consider first the $\rho$-type firm's expected payoff from the efficient strategy. The probability of two $\rho$ signals given a $\rho$ signal is

$$
\begin{aligned}
\operatorname{Pr}(\rho \rho \mid \rho) & =\operatorname{Pr}(\rho \mid R) \operatorname{Pr}(R \mid \rho)+\operatorname{Pr}(\rho \mid G) \operatorname{Pr}(G \mid \rho)=\sigma \operatorname{Pr}(R \mid \rho)+(1-\sigma) \operatorname{Pr}(G \mid \rho) \\
& =\sigma\left[\frac{\sigma(1-\mu)}{\sigma(1-\mu)+(1-\sigma) \mu}\right]+(1-\sigma)\left[\frac{(1-\sigma) \mu}{(1-\sigma) \mu+\sigma(1-\mu)}\right] \\
& =\frac{\sigma^{2}(1-\mu)+(1-\sigma)^{2} \mu}{\sigma(1-\mu)+(1-\sigma) \mu} .
\end{aligned}
$$


In this case, the firms share the payoff, which has an expected value of $\operatorname{Pr}(R \mid \rho \rho)$. The probability of a $\gamma$ signal and a $\rho$ signal given a $\rho$ signal is

$$
\begin{aligned}
\operatorname{Pr}(\gamma \rho \mid \rho) & =\operatorname{Pr}(\gamma \mid R) \operatorname{Pr}(R \mid \rho)+\operatorname{Pr}(\gamma \mid G) \operatorname{Pr}(G \mid \rho)=(1-\sigma) \operatorname{Pr}(R \mid \rho)+\sigma \operatorname{Pr}(G \mid \rho) \\
& =(1-\sigma)\left[\frac{\sigma(1-\mu)}{\sigma(1-\mu)+(1-\sigma) \mu}\right]+\sigma\left[\frac{(1-\sigma) \mu}{(1-\sigma) \mu+\sigma(1-\mu)}\right] \\
& =\frac{\sigma(1-\sigma)}{\sigma(1-\mu)+(1-\sigma) \mu} .
\end{aligned}
$$

In this case, the payoff to the firm that receives the $\rho$ signal is zero. Hence, the expected payoff from efficient investment for a firm that receives a $\rho$ signal is

$$
\Pi^{\rho^{*}}=\operatorname{Pr}(\rho \rho \mid \rho)\left[\frac{1}{4} \operatorname{Pr}(R \mid \rho \rho)\right]+\operatorname{Pr}(\gamma \rho \mid \rho) \cdot 0=\frac{1}{4}[\operatorname{Pr}(\rho \rho \mid \rho) \operatorname{Pr}(R \mid \rho \rho)] .
$$

The expected payoff from a mixed strategy is simply a convex combination of the payoffs from the two pure strategies. Therefore, to examine the strategic stability of the efficient outcome, we only need to consider a deviation from the other pure strategy $\beta^{\rho}=1$. If the other firm receives a $\gamma$ signal, then the two firms share the payoff, which has an expected value of $\operatorname{Pr}(G \mid \gamma \rho)$. If the other firm receives a $\rho$ signal, then by deviating and offering the green project the firm captures the entire payoff, which has an expected value of $\operatorname{Pr}(G \mid \rho \rho)$. Hence, the expected payoff for a firm that receives a $\rho$ signal and offers the green project is

$$
\begin{aligned}
\Pi^{\rho^{D}} & =\operatorname{Pr}(\gamma \rho \mid \rho)\left[\frac{1}{4} \operatorname{Pr}(G \mid \gamma \rho)\right]+\operatorname{Pr}(\rho \rho \mid \rho)\left[\frac{1}{2} \operatorname{Pr}(G \mid \rho \rho)\right] \\
& =\frac{1}{4}[\operatorname{Pr}(\gamma \rho \mid \rho) \mu+2 \operatorname{Pr}(\rho \rho \mid \rho) \operatorname{Pr}(G \mid \rho \rho)] .
\end{aligned}
$$

The expected net benefit of offering the green project instead of the red project when the firm receives a $\rho$ signal is the difference between (2) and (1):

$$
\begin{aligned}
\Pi^{\rho^{D}}-\Pi^{\rho^{*}} & =\frac{1}{4}[\operatorname{Pr}(\gamma \rho \mid \rho) \mu+2 \operatorname{Pr}(\rho \rho \mid \rho) \operatorname{Pr}(G \mid \rho \rho)]-\frac{1}{4}[\operatorname{Pr}(\rho \rho \mid \rho) \operatorname{Pr}(R \mid \rho \rho)] \\
& =\frac{1}{4}\{\operatorname{Pr}(\gamma \rho \mid \rho) \mu-\operatorname{Pr}(\rho \rho \mid \rho)[\operatorname{Pr}(R \mid \rho \rho)-2 \operatorname{Pr}(G \mid \rho \rho)]\} \\
& =\frac{1}{4}\left[\frac{1}{(1-\sigma) \mu+\sigma(1-\mu)}\right]\left\{2 \sigma^{2}\left(\mu-\frac{1}{2}\right)-3 \mu\left(\sigma-\frac{2}{3}\right)\right\} .
\end{aligned}
$$


The bracketed expression is strictly positive, so the sign of the entire expression depends on the sign of the expression in braces.

Let $\mathcal{H}$ denote the expression in braces. This function is strictly increasing in $\mu$ :

$$
\begin{aligned}
\frac{\partial \mathcal{H}}{\partial \mu} & =2 \sigma^{2}-3\left(\sigma-\frac{2}{3}\right) \\
& =2-\sigma(3-2 \sigma)>2-(3-2 \sigma)>2-(3-1)=0 .
\end{aligned}
$$

It is strictly decreasing in $\sigma$ :

$$
\frac{\partial \mathcal{H}}{\partial \sigma}=4 \sigma\left(\mu-\frac{1}{2}\right)-3 \mu<4\left(\mu-\frac{1}{2}\right)-3 \mu=\mu-2<0 .
$$

Moreover, it is easy to verify that $\mathcal{H}$ is strictly negative when $\mu=\frac{1}{2}$ and when $\sigma=1$, and that it is strictly positive when $\mu=\sigma$. Therefore, the Intermediate Value Theorem implies that for each value of $\mu(\sigma)$, there exists a unique threshold value of $\sigma(\mu)$, call it $\widehat{\sigma}(\widehat{\mu})$, that makes $\mathcal{H}=0$. When $\sigma<\widehat{\sigma}(\mu>\widehat{\mu}) \mathcal{H}$ is strictly positive, and when $\sigma>\widehat{\sigma}(\mu<\widehat{\mu}) \mathcal{H}$ is strictly negative.

The parameter space can thus be split into two regions, one region (high $\sigma$ and low $\mu$ ) where the efficient outcome is an equilibrium and one region (low $\sigma$ and high $\mu$ ) where it is not. The boundary between the two regions is implicitly defined by the net benefit from deviation being equal to zero, which happens when

$$
\mathcal{H}=2 \sigma^{2}\left(\mu-\frac{1}{2}\right)-3 \mu\left(\sigma-\frac{2}{3}\right)=0 .
$$

It is easy to verify that the end points of the boundary are $\left(\mu=\frac{1}{2}, \sigma=\frac{2}{3}\right)$ and $(\mu=1, \sigma=1)$. It is also easy to verify that for any admissible $\sigma$ and $\mu, \mathcal{H} \leq 2$. Finally, to analyze the slope of this boundary, notice that along it $\mathcal{H}=0$. This implies that when the partial derivatives of the net benefit of deviation with respect to $\sigma$ and $\mu$ are evaluated at the boundary, the effects of the parameters on the first multiplicative term, $\frac{1}{(1-\sigma) \mu+\sigma(1-\mu)}$ vanish. Hence, the partial derivatives of the net benefit with respect $\sigma$ and $\mu$ take on the same sign as $\frac{\partial \mathcal{H}}{\partial \sigma}$ and $\frac{\partial \mathcal{H}}{\partial \mu}$, respectively. It now follows from the Implicit Function Theorem that

$$
\frac{\mathrm{d} \widehat{\sigma}}{\mathrm{d} \widehat{\mu}}=-\left.\frac{\frac{\mathrm{d} \mathcal{H}}{\mathrm{d} \mu}}{\frac{\mathrm{d} \mathcal{H}}{\mathrm{d} \sigma}}\right|_{\mathcal{H}=0}>0
$$


Proof of Proposition 2: Consider first the part of the parameter space where the first-best efficient outcome is not an equilibrium. To confirm that the proposed equilibrium is strategically stable, start from the end of the game with the consumer's decision when both projects are offered. Call the firm offering the green project $i$ and the firm offering the red project $j$. The consumer's payoff from the green project is proportional to the probability that the state is green, and therefore her best-response correspondence is

$$
\alpha^{*} \in\left\{\begin{array}{cc}
\{1\} & \text { if } \operatorname{Pr}(G \mid g, r)>\frac{1}{2} \\
(0,1) & \text { if } \operatorname{Pr}(G \mid g, r)=\frac{1}{2} \\
\{0\} & \text { if } \operatorname{Pr}(G \mid g, r)<\frac{1}{2} .
\end{array}\right.
$$

In the proposed equilibrium, the red project is chosen with positive probability, so $\operatorname{Pr}(G \mid g, r)$ is given by Bayes Rule, amended by the Intuitive Criterion if $\beta_{j}^{\rho}=1$ :

$$
\begin{aligned}
\operatorname{Pr}(G \mid g, r) & =\frac{\operatorname{Pr}(g \mid G) \operatorname{Pr}(r \mid G) \operatorname{Pr}(G)}{\operatorname{Pr}(g \mid G) \operatorname{Pr}(r \mid G) \operatorname{Pr}(G)+\operatorname{Pr}(g \mid R) \operatorname{Pr}(r \mid R) \operatorname{Pr}(R)} \\
& =\frac{(1-\sigma) \mu\left[\sigma+(1-\sigma) \beta_{i}^{\rho}\right]}{(1-\sigma) \mu\left[\sigma+(1-\sigma) \beta_{i}^{\rho}\right]+\sigma(1-\mu)\left[(1-\sigma)+\sigma \beta_{i}^{\rho}\right]} \\
& =\operatorname{Pr}(G \mid g, \rho) .
\end{aligned}
$$

The $\operatorname{Pr}(G \mid g, r)$ is strictly decreasing and strictly convex in $\beta_{i}^{\rho}$ :

$$
\begin{aligned}
& \frac{\partial \operatorname{Pr}(G \mid g, r)}{\partial \beta_{i}^{\rho}}=\frac{-\sigma(1-\sigma) \mu(1-\mu)\left[\sigma^{2}-(1-\sigma)^{2}\right]}{\left\{\left[\sigma+(1-\sigma) \beta_{i}^{\rho}\right](1-\sigma) \mu+\left[(1-\sigma)+\sigma \beta_{i}^{\rho}\right](1-\mu)\right\}^{2}}<0 \\
& \frac{\partial^{2} \operatorname{Pr}(G \mid g, r)}{\partial \beta_{i}^{\rho 2}}=\frac{2 \sigma(1-\sigma) \mu(1-\mu)\left[(1-\sigma)^{2} \mu+\sigma^{2}(1-\mu)\right]}{\left\{\left[\sigma+(1-\sigma) \beta_{i}^{\rho}\right](1-\sigma) \mu+\left[(1-\sigma)+\sigma \beta_{i}^{\rho}\right](1-\mu)\right\}^{3}}>0 .
\end{aligned}
$$

Moreover, it is easy to verify that $\operatorname{Pr}(G \mid g, r)$ is strictly greater than $\frac{1}{2}$ when $\beta_{i}^{\rho}=1$ and is strictly less than $\frac{1}{2}$ when $\beta_{i}^{\rho}=0$. It follows from the Intermediate Value Theorem that there exists a unique $\beta_{i}^{\rho}$ for which $\operatorname{Pr}(G \mid g, r)=\frac{1}{2}$. At this value 
of $\beta_{i}^{\rho}$, which we will denote by $\widehat{\beta}_{i}^{\rho}$, the consumer switches from choosing the green project to choosing the red project.

A closed-form expression for $\widehat{\beta}_{i}^{\rho}$ can be derived based on equation (4)

$$
\begin{gathered}
\frac{(1-\sigma) \mu\left[\sigma+(1-\sigma) \widehat{\beta}_{i}^{\rho}\right]}{(1-\sigma) \mu\left[\sigma+(1-\sigma) \widehat{\beta}_{i}^{\rho}\right]+\sigma(1-\mu)\left[(1-\sigma)+\sigma \widehat{\beta}_{i}^{\rho}\right]}=\frac{1}{2} \Leftrightarrow \\
{\left[\sigma+(1-\sigma) \widehat{\beta}_{i}^{\rho}\right](1-\sigma) \mu=\left[(1-\sigma)+\sigma \widehat{\beta}_{i}^{\rho}\right] \sigma(1-\mu) \Leftrightarrow} \\
\widehat{\beta}_{i}^{\rho}=\frac{\sigma(1-\sigma)(2 \mu-1)}{\sigma^{2}(1-\mu)-(1-\sigma)^{2} \mu} .
\end{gathered}
$$

Since $\operatorname{Pr}(G \mid g, r)$ is strictly increasing in $\mu$ and strictly decreasing in $\sigma$, it follows from the Implicit Function Theorem that $\widehat{\beta}_{i}^{\rho}$ is strictly increasing in $\mu$ and strictly decreasing in $\sigma$.

To derive the $\rho$-type firm's expected net benefit from offering the green rather than the red project we need the following conditional probabilities:

$$
\begin{aligned}
& \operatorname{Pr}\left(g_{j} \mid \rho_{i}\right)=\frac{\sigma(1-\sigma)+\beta_{j}^{\rho}\left[\sigma^{2}(1-\mu)+(1-\sigma)^{2} \mu\right]}{\sigma(1-\mu)+(1-\sigma) \mu} \\
& \operatorname{Pr}\left(r_{j} \mid \rho_{i}\right)=\left(1-\beta_{j}^{\rho}\right)\left[\frac{\sigma^{2}(1-\mu)+(1-\sigma)^{2} \mu}{\sigma(1-\mu)+(1-\sigma) \mu}\right] \\
& \operatorname{Pr}\left(G \mid \rho_{i}, g_{j}\right)=\frac{\beta_{j}^{\rho}(1-\sigma)^{2} \mu+(1-\sigma) \sigma \mu}{(1-\sigma) \sigma+\beta_{j}^{\rho}\left[(1-\sigma)^{2} \mu+\sigma^{2}(1-\mu)\right]} \\
& \operatorname{Pr}\left(R \mid \rho_{i}, g_{j}\right)=\frac{\sigma(1-\sigma)(1-\mu)+\beta_{j}^{\rho} \sigma^{2}(1-\mu)}{\sigma(1-\sigma)+\beta_{j}^{\rho}\left[\sigma^{2}(1-\mu)+(1-\sigma)^{2} \mu\right]} \\
& \operatorname{Pr}\left(G \mid \rho_{i}, r_{j}\right)=\frac{(1-\sigma)^{2} \mu}{(1-\sigma)^{2} \mu+\sigma^{2}(1-\mu)} \quad \text { if } \beta_{j}^{\rho}<1 \\
& \operatorname{Pr}\left(R \mid \rho_{i}, r_{j}\right)=\frac{\sigma^{2}(1-\mu)}{\sigma^{2}(1-\mu)+(1-\sigma)^{2} \mu} \quad \text { if } \beta_{j}^{\rho}<1 .
\end{aligned}
$$


The $\rho$-type firm's net benefit from choosing the green project instead of the red project is

$$
\begin{aligned}
\Pi_{i,(g-r)}^{\rho}=\left\{\frac{1}{4} \operatorname{Pr}\left(g_{j} \mid \rho_{i}\right) \operatorname{Pr}\left(G \mid g_{j}, \rho_{i}\right)+\frac{\alpha}{2} \operatorname{Pr}\left(r_{j} \mid \rho_{i}\right) \operatorname{Pr}\left(G \mid r_{j}, \rho_{i}\right)\right\} \\
-\left\{\frac{1}{4} \operatorname{Pr}\left(r_{j} \mid \rho_{i}\right) \operatorname{Pr}\left(R \mid r_{j}, \rho_{i}\right)+\frac{(1-\alpha)}{2} \operatorname{Pr}\left(g_{j} \mid \rho_{i}\right) \operatorname{Pr}\left(G \mid g_{j}, \rho_{i}\right)\right\} \\
=\frac{1}{4}\left\{\operatorname{Pr}\left(g_{j} \mid \rho_{i}\right) \operatorname{Pr}\left(G \mid g_{j}, \rho_{i}\right)-\left[\operatorname{Pr}\left(r_{j} \mid \rho_{i}\right) \operatorname{Pr}\left(R \mid r_{j}, \rho_{i}\right)+2 \operatorname{Pr}\left(g_{j} \mid \rho_{i}\right) \operatorname{Pr}\left(R \mid g_{j}, \rho_{i}\right)\right]\right. \\
\left.+2 \alpha\left[\operatorname{Pr}\left(r_{j} \mid \rho_{i}\right) \operatorname{Pr}\left(G \mid r_{j}, \rho_{i}\right)+\operatorname{Pr}\left(g_{j} \mid \rho_{i}\right) \operatorname{Pr}\left(R \mid g_{j}, \rho_{i}\right)\right]\right\} .
\end{aligned}
$$

This net benefit is continuous and linearly increasing in $\alpha$.

If $\beta_{i}^{\rho}<\widehat{\beta}_{i}^{\rho}$, then $\alpha^{*}=1$. Hence, we can express the payoff as

$$
\begin{aligned}
& \Pi_{i,(g-r)}^{\rho}=\frac{1}{4}\left\{\left[\frac{\sigma(1-\sigma) \mu+\beta_{j}^{\rho}(1-\sigma)^{2} \mu}{\sigma(1-\mu)+(1-\sigma) \mu}\right]\right. \\
& \left.+2\left[\frac{\left(1-\beta_{j}^{\rho}\right)(1-\sigma)^{2} \mu}{\sigma(1-\mu)+(1-\sigma) \mu}\right]-\left[\frac{\left(1-\beta_{j}^{\rho}\right) \sigma^{2}(1-\mu)}{\sigma(1-\mu)+(1-\sigma) \mu}\right]\right\} \\
& =\frac{1}{4}\left[\frac{1}{\sigma(1-\mu)+(1-\sigma) \mu}\right]\left\{\left[2 \sigma^{2}\left(\mu-\frac{1}{2}\right)-3 \mu\left(\sigma-\frac{2}{3}\right)\right]+\beta_{j}^{\rho}\left[\sigma^{2}(1-\mu)-(1-\sigma)^{2} \mu\right]\right\} .
\end{aligned}
$$

Because $\sigma>\mu$, this expression is linearly decreasing in $\beta_{j}^{\rho}$, and by the assumption that the first-best efficient outcome is not strategically stable, the expression is strictly positive when $\beta_{j}^{\rho}=0$. This allows us to conclude that $\forall \beta_{i}^{\rho}<\widehat{\beta}_{i}^{\rho} \Rightarrow \Pi_{i,(g-r)}^{\rho}>$ 0 . Therefore, no such $\beta_{j}^{\rho}$ can be a best response.

If $\beta_{i}^{\rho}>\widehat{\beta}_{i}^{\rho}$, then $\alpha^{*}=0$. Hence, we can express the payoff as

$$
\begin{aligned}
& \Pi_{i,(g-r)}^{\rho}=\frac{1}{4}\left\{\operatorname{Pr}\left(g_{j} \mid \rho_{i}\right) \operatorname{Pr}\left(G \mid g_{j}, \rho_{i}\right)-\left[\operatorname{Pr}\left(r_{j} \mid \rho_{i}\right) \operatorname{Pr}\left(R \mid r_{j}, \rho_{i}\right)+2 \operatorname{Pr}\left(g_{j} \mid \rho_{i}\right) \operatorname{Pr}\left(R \mid g_{j}, \rho_{i}\right)\right]\right\} \\
& =-\frac{1}{4}\left[\frac{1}{\sigma(1-\mu)+(1-\sigma) \mu}\right]\left\{\sigma[2(1-\sigma)(1-\mu)+(\sigma-\mu)]+\beta_{j}^{\rho}\left[\sigma^{2}(1-\mu)-(1-\sigma)^{2} \mu\right]\right\} .
\end{aligned}
$$

Because $\sigma>\mu$, this expression is linearly decreasing in $\beta_{j}^{\rho}$ and is strictly negative when $\beta_{j}^{\rho}=0$. This allows us to conclude that $\forall \beta_{i}^{\rho}>\widehat{\beta}_{i}^{\rho} \Rightarrow \Pi_{i,(g-r)}^{\rho}<0$. Therefore, no such $\beta_{i}^{\rho}$ can be a best response. 
Thus, the only remaining candidate for an equilibrium strategy for the $\rho$-type firm is $\widehat{\beta}_{i}^{\rho}$, which makes the consumer indifferent between the green and red project. Moreover, it follows from the Intermediate Value Theorem that there exists a unique $\alpha^{*}$ that makes the $\rho$-type firm indifferent between the green and the red project. For $\Pi_{i,(g-r)}^{\rho}=0$ we have

$$
\begin{aligned}
\alpha^{*} & =\frac{1}{2}\left\{\frac{\operatorname{Pr}\left(r_{j} \mid \rho_{i}\right) \operatorname{Pr}\left(R \mid r_{j}, \rho_{i}\right)+2 \operatorname{Pr}\left(g_{j}, \rho_{i}\right) \operatorname{Pr}\left(R \mid g_{j}, \rho_{i}\right)-\operatorname{Pr}\left(g_{j} \mid \rho_{i}\right) \operatorname{Pr}\left(G \mid g_{j}, \rho_{i}\right)}{\operatorname{Pr}\left(r_{j} \mid \rho_{i}\right) \operatorname{Pr}\left(G \mid r_{j}, \rho_{i}\right)+\operatorname{Pr}\left(g_{j} \mid \rho_{i}\right) \operatorname{Pr}\left(R \mid g_{j}, \rho_{i}\right)}\right\} \\
& =\frac{1}{2}\left\{1+\frac{\sigma-\mu}{(1-\sigma)[(1-\sigma) \mu+\sigma(1-\mu)]+\beta_{j}^{\rho}\left[\sigma^{2}(1-\mu)-(1-\sigma)^{2} \mu\right]}\right\}>\frac{1}{2} .
\end{aligned}
$$

Since $\widehat{\beta}_{i}^{\rho}$ is unique and depends only on the information structure, it must be the equilibrium choice of both firms if they receive a $\rho$ signal. Therefore, in equilibrium, $\beta_{i}^{\rho^{*}}=\beta_{j}^{\rho^{*}}=\widehat{\beta}_{i}^{\rho} \equiv \widehat{\beta}^{\rho}$ and

$$
\begin{aligned}
\alpha^{*} & =\frac{1}{2}\left\{1+\left[\frac{\sigma-\mu}{(1-\sigma)[(1-\sigma) \mu+\sigma(1-\mu)]+{\widehat{\beta^{\rho}}}_{i}\left[\sigma^{2}(1-\mu)-(1-\sigma)^{2} \mu\right]}\right]\right\} \\
& =\frac{1}{2}\left(\frac{\sigma}{1-\sigma}\right)\left(\frac{1-\mu}{\mu}\right) .
\end{aligned}
$$

By assumption, the condition for an inefficient outcome derived in Proposition 1 is satisfied. This in turn implies that $\left(\frac{\sigma}{1-\sigma}\right)\left(\frac{1-\mu}{\mu}\right)<2$, so $\alpha^{*} \in\left(\frac{1}{2}, 1\right)$.

The expected efficiency loss can be derived as follows

$$
\begin{aligned}
\mathrm{E}\left[\Pi\left(\beta^{*}\right)\right] & =\mu\left[\sigma \beta^{\gamma^{*}}+(1-\sigma) \beta^{\rho^{*}}\right]+(1-\mu)\left[(1-\sigma)\left(1-\beta^{\gamma^{*}}\right)+\sigma\left(1-\beta^{\rho^{*}}\right)\right] \\
& =\mu\left[\sigma+(1-\sigma) \widehat{\beta}^{\rho}\right]+(1-\mu)\left[\sigma\left(1-\widehat{\beta}^{\rho}\right)\right] \\
& =\sigma-\widehat{\beta}^{\rho}(\sigma-\mu) .
\end{aligned}
$$

Hence, the welfare loss can be calculated as the difference between the first-best efficient equilibrium in which information is fully revealed and this last expression

$$
W \equiv \mathrm{E}\left[\Pi\left(\beta^{* *}\right)\right]-\mathrm{E}\left[\Pi\left(\beta^{*}\right)\right]=\sigma-\left[\sigma-\widehat{\beta}^{\rho}(\sigma-\mu)\right]=(\sigma-\mu) \widehat{\beta}^{\rho} .
$$

To argue that the above equilibrium is unique, recall from Proposition 1 that when it obtains, the perfectly-separating first-best efficient outcome is not strategically stable. Furthermore, notice that for any given strategy profile, the net payoff 
from choosing the green rather than the red project is strictly higher for the $\gamma$-type firm than for the $\rho$-type firm. It therefore follows that $\beta^{\gamma^{*}} \geq \beta^{\rho^{*}}$ and that at most one firm-type can play a mixed strategy. Hence, apart from the above equilibrium, there exists no other in which the $\rho$-type firm plays a mixed strategy. Moreover, the discussion above also ruled out the perfectly-pooling equilibrium in which both firm-types choose the green project.

Next, consider the possibility that the $\gamma$-type firm plays a mixed strategy in equilibrium: $\beta^{\gamma^{*}} \in(0,1) \Rightarrow \beta^{\rho^{*}}=0$. With $\beta^{\rho^{*}}=0$, choosing the green project perfectly reveals that the firm's signal is $\gamma$, so the consumer strictly prefers the green project to the red one. But this implies that the $\gamma$-type firm also strictly prefers the green project to the red one, i.e., $\beta^{\gamma^{*}} \in(0,1)$ cannot be sequentially rational. Moreover, the Intuitive Criterion ensures that the $\gamma$-type firm enjoys the same benefit from, and incentive to deviate to, the green project in the perfectly pooling outcome in which both firm-types invest in the red project. 


\section{B The Number of Competing Firms}

To get a sense of how the analysis changes when the number of firms increases, we outline the analysis of the problem when there are four firms. ${ }^{10}$ Intuitively, increasing the number of firms decreases the $\rho$-type firm's net benefit from choosing the green project. This shifts down the net-benefit curve in Figure 2, panel A, and, as a consequence, the inefficiency region in Figure 1 shrinks. However, it leaves unaffected $\widehat{\beta}^{\rho}$, which is determined by a single deviating firm's influence on the consumer's inference about the true state of the world.

We therefore want to demonstrate that the $\rho$-type firm's net benefit from unilateral deviation from the efficient outcome is strictly larger with two firms than with four. When there are two firms, this net benefit looks as follows:

$$
\left(\frac{1}{4}\right)\{\operatorname{Pr}(\gamma \rho \mid \rho) \operatorname{Pr}(G \mid \gamma \rho)+\operatorname{Pr}(\rho \rho \mid \rho)[2 \operatorname{Pr}(G \mid \rho \rho)-\operatorname{Pr}(R \mid \rho \rho)]\} .
$$

The leading one-quarter is the firm's share of the investment payoff when the market is shared evenly. The first term inside the brackets is the benefit from capturing half the market with the green project rather than none of it with the red project when the other firm offers the green project. The second term represents the net benefit when both firms receive a $\rho$ signal. In this state, the green project once again gives a larger market share than the red one, namely the entire market instead of only half of it, but also has a lower expected value since it contradicts two $\rho$-signals.

\footnotetext{
${ }^{10}$ If there is an odd number of firms, then the inefficiency disappears completely. The reason for this is that with an odd number of firms, the aggregate private information of the firms always favors one project over the other. This means that the pivotal firm whose private information - as inferred by the consumer - determines the consumer's choice can sway the consumer no matter which signal she reveals. Therefore, there is no incentive for the pivotal firm to misrepresent her information. In contrast, when the number of firms is even, the pivotal firm's true private information makes for a cancellation of the firms' signals taken together, leaving it up to the uninformed, but opinionated consumer to determine the choice of investment project.
} 
Consider next the same net benefit from deviation when there are four firms:

$$
\begin{aligned}
\left(\frac{1}{8}\right)\left\{\operatorname{Pr}(\gamma \gamma \rho \rho \mid \rho)\left(\frac{4}{3}\right)\right. & \operatorname{Pr}(G \mid \gamma \gamma \rho \rho) \\
+ & \operatorname{Pr}(\gamma \rho \rho \rho \mid \rho)\left[2 \operatorname{Pr}(G \mid \gamma \rho \rho \rho)-\left(\frac{4}{3}\right) \operatorname{Pr}(R \mid \gamma \rho \rho \rho)\right] \\
& +[\operatorname{Pr}(\gamma \gamma \gamma \rho \mid \rho) \operatorname{Pr}(G \mid \gamma \gamma \gamma \rho)-\operatorname{Pr}(\rho \rho \rho \rho \mid \rho) \operatorname{Pr}(R \mid \rho \rho \rho \rho)]\} .
\end{aligned}
$$

Again, the leading multiplicative term scales the payoff to each firm's baseline market share when the market is shared equally. The first two terms are similar to the ones when there are two firms. The first term captures the net benefit from getting a part of the market rather than nothing when the aggregate private information is uninformative and two other firms are offering the green project. Notice that the market share in this case is higher than one-eighth since one firm fails to share in the payoff by offering the red project. The second term represents the net benefit when the aggregate information sums to two $\rho$-signals. Just as in the two-firm case, the $\rho$-type firm's decision is critical for the consumer's preference over the two projects, so the green project, which shares the market with one other firm, captures a larger market share than the red one, which shares the market with two other firms. Finally, the last term does not appear when there are only two firms. This captures the benefit when the aggregate information is so unambiguously in favor of one of the projects that a single firm's decision is unable to change the consumer's beliefs enough to alter her ranking of the two projects. This happens when the other three firms have the same signal. In this case, the firm's market share is one-fourth if it offers the same project as the other three firms and is zero if it offers a different one. Therefore, the net benefit from offering the green project instead of the red one amounts to trading equal shares of a project with a high expected value for one with a low expected value.

Compare term-by-term the net benefit from deviation with two and four firms. With two firms, the first term looks as follows:

$$
\left(\frac{1}{4}\right) \operatorname{Pr}(\gamma \rho \mid \rho) \operatorname{Pr}(G \mid \gamma \rho)=\left(\frac{1}{4}\right)\left[\frac{\sigma(1-\sigma)}{\sigma(1-\mu)+(1-\sigma) \mu}\right] \mu .
$$


With four firms, the first term is

$$
\begin{aligned}
\left(\frac{1}{8}\right) \operatorname{Pr}(\gamma \gamma \rho \rho \mid \rho)\left(\frac{4}{3}\right) \operatorname{Pr}(G \mid \gamma \gamma \rho \rho) & =\left(\frac{1}{8}\right)\left[\frac{3 \sigma^{2}(1-\sigma)^{2}}{\sigma(1-\mu)+(1-\sigma) \mu}\right]\left(\frac{4}{3}\right) \mu \\
& =2 \sigma(1-\sigma)\left\{\left(\frac{1}{4}\right)\left[\frac{\sigma(1-\sigma)}{\sigma(1-\mu)+(1-\sigma) \mu}\right] \mu\right\} .
\end{aligned}
$$

Since $2 \sigma(1-\sigma)<1$, this expression is strictly smaller than the corresponding expression when there are two firms.

The second term looks as follows when there are two firms

$$
\begin{aligned}
& \left(\frac{1}{4}\right) \operatorname{Pr}(\rho \rho \mid \rho)\{2 \operatorname{Pr}(G \mid \rho \rho)-\operatorname{Pr}(R \mid \rho \rho)\} \\
& =\left(\frac{1}{4}\right)\left[\frac{\sigma^{2}(1-\mu)+(1-\sigma)^{2} \mu}{\sigma(1-\mu)+(1-\sigma) \mu}\right]\left\{2\left[\frac{(1-\sigma)^{2} \mu}{(1-\sigma)^{2} \mu+\sigma^{2}(1-\mu)}\right]-\left[\frac{\sigma^{2}(1-\mu)}{\sigma^{2}(1-\mu)+(1-\sigma)^{2} \mu}\right]\right\} \\
& =\left(\frac{1}{4}\right)\left[\frac{1}{\sigma(1-\mu)+(1-\sigma) \mu}\right]\left[2(1-\sigma)^{2} \mu-\sigma^{2}(1-\mu)\right] .
\end{aligned}
$$

With four firms, the second term is

$$
\begin{aligned}
& \left(\frac{1}{8}\right) \operatorname{Pr}(\gamma \rho \rho \rho \mid \rho)\left\{2 \operatorname{Pr}(G \mid \gamma \rho \rho \rho)-\left(\frac{4}{3}\right) \operatorname{Pr}(R \mid \gamma \rho \rho \rho)\right\} \\
& =\left(\frac{1}{8}\right)\left[\frac{3 \sigma(1-\sigma)\left[\sigma^{2}(1-\mu)+(1-\sigma)^{2} \mu\right]}{\sigma(1-\mu)+(1-\sigma) \mu}\right]\left\{2\left[\frac{(1-\sigma)^{2} \mu}{(1-\sigma)^{2} \mu+\sigma^{2}(1-\mu)}\right]-\left(\frac{4}{3}\right)\left[\frac{\sigma^{2}(1-\mu)}{\sigma^{2}(1-\mu)+(1-\sigma)^{2} \mu}\right]\right\} \\
& =\left(\frac{3}{2}\right) \sigma(1-\sigma)\left\{\left(\frac{1}{4}\right)\left[\frac{1}{\sigma(1-\mu)+(1-\sigma) \mu}\right]\left[2(1-\sigma)^{2} \mu-\left(\frac{4}{3}\right) \sigma^{2}(1-\mu)\right]\right\} \\
& <\left(\frac{3}{2}\right) \sigma(1-\sigma)\left\{\left(\frac{1}{4}\right)\left[\frac{1}{\sigma(1-\mu)+(1-\sigma) \mu}\right]\left[2(1-\sigma)^{2} \mu-\sigma^{2}(1-\mu)\right]\right\} .
\end{aligned}
$$

Since $\left(\frac{3}{2}\right) \sigma(1-\sigma)<1$, this expression is strictly smaller than the corresponding expression with only two firms.

Finally, it is easy to confirm the economic intuition that the third and last term of the net benefit with four firms is strictly negative

$$
\begin{aligned}
& \left(\frac{1}{8}\right)\{\operatorname{Pr}(\gamma \gamma \gamma \rho \mid \rho) \operatorname{Pr}(G \mid \gamma \gamma \gamma \rho)-\operatorname{Pr}(\rho \rho \rho \rho \mid \rho) \operatorname{Pr}(R \mid \rho \rho \rho \rho)\} \\
& =\left(\frac{1}{8}\right)\left\{\left[\frac{\sigma(1-\sigma)\left[\sigma^{2} \mu+(1-\sigma)^{2}(1-\mu)\right]}{\sigma(1-\mu)+(1-\sigma) \mu}\right]\left[\frac{\sigma^{2} \mu}{\sigma^{2} \mu+(1-\sigma)^{2}(1-\mu)}\right]-\left[\frac{(1-\sigma)^{4} \mu+\sigma^{4}(1-\mu)}{\sigma(1-\mu)+(1-\sigma) \mu}\right]\left[\frac{\sigma^{4}(1-\mu)}{\sigma^{4}(1-\mu)+(1-\sigma)^{4} \mu}\right]\right\} \\
& =\left(\frac{1}{8}\right)\left[\frac{1}{\sigma(1-\mu)+(1-\sigma) \mu}\right]\left[\sigma^{3}(1-\sigma) \mu-\sigma^{4}(1-\mu)\right] \\
& =\left(\frac{1}{8}\right)\left[\frac{\sigma^{3}}{\sigma(1-\mu)+(1-\sigma) \mu}\right](\mu-\sigma)<1 .
\end{aligned}
$$

Therefore, the $\rho$-type firm's net benefit from unilateral deviation from the efficient outcome is strictly greater with two firms than with four firms. 


\section{References}

Brandenburger, Adam and Ben Polak (1996). When managers cover their posteriors: Making the decisions the market wants to see. RAND Journal of Economics 27(3): 523-41.

Caplin, Andrew and Barry Nalebuff (1991). Aggregation and imperfect competition: On the existence of equilibrium. Econometrica 59(1): 25-59.

d'Aspremont, Claude, Jean Jaskold Gabszewicz, and Jacques-François Thisse (1979). On Hotelling's 'Stability in competition'. Econometrica 47(5): 11451150 .

Dulleck, Uwe and Rudolf Kerschbamer (2001). On doctors, mechanics and computer specialists. Or where are the problems with credence goods? CEPR Discussion Paper No. 2016.

Eaton, B. Curtis and Richard G. Lipsey (1975). The principle of minimum differentiation reconsidered: Some new developments in the theory of spatial competition. Review of Economic Studies 42(1): 27-49.

Eaton, B. Curtis and Richard G. Lipsey (1989). Product differentiation. In R. Schmalensee and R. D. Willig (Eds.), Handbook of Industrial Organization, Volume 1. Amsterdam: Elsevier Science Publishers.

Grant, Simon, Stephen King, and Ben Polak (1996). Information externalities, shareprice incentives and managerial behavior. Journal of Economic Surveys 10(1): $1-22$.

Heidhues, Paul and Johan Lagerlöf (2002). Hiding information in electoral competition. Games and Economic Behavior, forthcoming.

Holmström, Bengt (1982). Managerial incentive problems: A dynamic perspective. In Essays in Economics and Management in Honour of Lars Wahlbeck. Helsinki: Swedish School of Economics. 
Holmström, Bengt and Paul Milgrom (1991). Multi-task principal-agent analysis: Incentive contracts, asset ownership, and job design. Journal of Law, Economics, and Organization 7(1): 24-52.

Hotelling, Harold (1929). Stability in competition. Economic Journal 39(153): 4157.

Lazear, Edward P. (1989). Pay equality and industrial politics. Journal of Political Economy 97(3): 561-580.

Lazear, Edward P. and Sherwin Rosen (1981). Rank-order tournaments as optimum labor contracts. Journal of Political Economy 89(5): 841-64.

Milgrom, Paul (1988). Employment contracts, influence activities, and efficient organization design. Journal of Political Economy 96(1): 42-60.

Milgrom, Paul and John Roberts (1988). An economic approach to influence in organizations. American Journal of Sociology 94: S157-79.

Milgrom, Paul and John Roberts (1992). Economics, Organization, and Management. Upper Saddle River: Prentice-Hall.

Morris, Stephen (2001). Political correctness. Journal of Political Economy 109(2): $231-265$.

Prendergast, Canice (1993). A theory of 'yes men'. American Economic Review 83(4): $757-70$.

Scharfstein, David S. and Jeremy C. Stein (1990). Herd behavior and investment. American Economic Review 80(3): 465-79.

Tirole, Jean (1988). The Theory of Industrial Organization. Cambridge, MA: MIT Press.

Tirole, Jean (1992). Collusion and the theory of organization. In J.-J. Laffont (Ed.), Advances in Economic Theory: Sixth World Congress, Volume 2. Cambridge: Cambridge University Press. 